\title{
Double blind randomised placebo controlled trial of adjunctive prednisolone in the treatment of effusive tuberculous pericarditis in HIV seropositive patients
}

\author{
J G Hakim, I Ternouth, E Mushangi, S Siziya, V Robertson, A Malin
}

\begin{abstract}
Objective-To determine the effect of adjunctive prednisolone on morbidity, pericardial fluid resolution, and mortality in HIV seropositive patients with effusive tuberculous pericarditis.

Design-Double blind randomised placebo controlled trial.

Setting-Two medical school affiliated referral hospitals in Harare, Zimbabwe.

Patients-58 HIV seropositive patients aged 18-55 years with tuberculous pericarditis.

Interventions-All patients received standard short course antituberculous chemotherapy and were randomly assigned to receive prednisolone or placebo for six weeks.

Main outcome measures-Clinical improvement, echocardiographic and radiologic pericardial fluid resolution, and death.

Results-29 patients were assigned to prednisolone and 29 to placebo. After 18 months of follow up there were five deaths in the prednisolone treated group and 10 death in the placebo group. Mortality was significantly lower in the prednisolone group $\left(\log \operatorname{rank} \chi^{2}=8.19, \mathrm{df}=1\right.$, $\mathrm{p}=0.004)$. Resolution of raised jugular venous pressure $(\mathrm{p}=0.017)$, hepatomegaly $(\mathrm{p}=0.007)$, and ascites $(p=0.015)$, and improvement in physical activity $(p=0.02)$, were significantly more rapid in the prednisolone treated patients. However, there was no difference in the rate of radiologic and echocardiographic resolution of pericardial effusion.

Conclusions-Adjunctive prednisolone for effusive tuberculous pericarditis produced a pronounced reduction in mortality. It is suggested prednisolone should be added to standard short course chemotherapy to treat HIV related effusive tuberculous pericarditis.

(Heart 2000;84:183-188)
\end{abstract}

Keywords: tuberculous pericarditis; HIV infection; echocardiography; prednisolone

There has been a major increase in the incidence of tuberculosis in the past decade, largely as a result of the HIV epidemic. ${ }^{1-3}$ In particular the proportion of tuberculosis patients presenting with extrapulmonary disease has increased. ${ }^{4}$ Several reports have documented the relation of pericardial tuberculosis and HIV infection, with seropositivity being observed in $67-92 \%$ of patients. ${ }^{5-7}$ Survival is adversely affected in patients co-infected with tuberculosis and HIV. ${ }^{8}$

The treatment of tuberculous pericarditis in HIV seronegative individuals consists of standard antituberculous chemotherapy, including currently accepted short course regimens. ${ }^{9-11}$ This treatment has been extended to HIV seropositive individuals, and the impression is that the outcome of treatment may be as good as in HIV seronegative patients, at least in the short term. ${ }^{2}{ }^{4}$ However, HIV seropositive patients have a higher rate of side effects from standard treatment regimens, and there is concern that these patients may have a higher relapse rate. ${ }^{4}$ Another concern is that the use of adjunctive corticosteroids in HIV seropositive individuals may increase the risk of bacterial and viral infections and Kaposi's sarcoma. ${ }^{12}{ }^{13}$ Moreover, use of adjunctive corticosteroids in tuberculous pericarditis remains controversial, even in non-HIV infected individuals. ${ }^{10-14}$ In non-randomised ${ }^{15-17}$ and randomised stud- ies $^{18}{ }^{19}$ of tuberculous pericarditis, rapid improvement of symptoms and reduced mortality has been suggested with the use of adjunctive corticosteroids in non-HIV infected individuals. A systematic review of 543 patients in three trials, however, concluded that prednisolone has no clear beneficial effect in patients with tuberculous pericarditis. ${ }^{20}$ None of these studies, however, addressed HIV seropositive patients, yet at present the greatest impact of tuberculous pericarditis is among HIV seropositive individuals. The aim of this study was, therefore, to determine the effect of adjunctive prednisolone on morbidity, pericardial fluid resolution, and mortality in HIV seropositive individuals with tuberculous pericarditis treated with a standard antituberculous regimen.

\section{Subjects and methods}

DESIGN

This was a double blind randomised placebo controlled trial of patients with tuberculous pericarditis and HIV infection. Patients were enrolled at two medical school affiliated referral hospitals in Harare city. Ethical approval was obtained from the Zimbabwe Medical Research Council. All patients gave written informed consent and received counselling for HIV antibody testing. Patients who declined testing were not entered into the trial. 
PATIENTS

Eligibility criteria were: (a) age $18-55$ years; (b) residence in Harare city to ensure good follow up; (c) HIV seropositive; (d) no diagnosis of tuberculosis within the past two years; (e) large pericardial effusion on echocardiography ( $>1 \mathrm{~cm}$ anteriorly and $>1 \mathrm{~cm}$ posteriorly; and (f) pericardial aspirate with $>50 \%$ lymphocytes and protein content $>30 \mathrm{~g} / \mathrm{l}$. Exclusion criteria were: (a) antituberculous treatment started more than 48 hours before recruitment; (b) corticosteroid treatment within previous one month; (c) presence of Kaposi's sarcoma or any other malignancy; (d) coexisting life threatening disease; (e) bacterial pneumonia; (f) pregnancy; (g) cavitating pulmonary tuberculosis; and (h) other causes of pericardial effusion.

Demographic and clinical characteristics were obtained at baseline, including HIV related features.

DEFINITION OF PERICARDIAL TUBERCULOSIS

Patients were admitted into the study on the basis of an echocardiographic demonstration of a large fibrinous pericardial effusion and a clinical diagnosis of tuberculous pericarditis, supported by a high lymphocyte count and a high protein content in the pericardial aspirate. Diagnostic and/or therapeutic pericardiocentesis was undertaken in all patients. The typical two dimensional (cross sectional) echocardiography appearance of tuberculous pericarditis was a thickened pericardium with layers of shaggy echoes lining both visceral and parietal pericardium as previously described, ${ }^{21}$ but various appearances were observed. Clinical examination and appropriate tests excluded alternative causes of pericarditis.

TREATMENT AND RANDOMISATION TO

PREDNISOLONE

All patients received a standard short course anti tuberculous regimen in accordance with national guidelines. ${ }^{22}$ This included rifampicin, isoniazid, pyrazinamide, and ethambutol for two months, followed by rifampicin and isoniazid for a further four months in standard doses. Prednisolone and placebo were made as identical " $5 \mathrm{mg}$ " tablets. The intervention consisted of prednisolone/placebo tablets starting at a dose of $60 \mathrm{mg}$ (12 tablets) and tapering by $10 \mathrm{mg}$ per week until completion at the end of the sixth week. Randomisation was achieved by the use of a computer generated randomisation list with an equal number of patients assigned to receive prednisolone and placebo. Prednisolone/placebo packages were prepared according to the randomisation list, but labelled with the study number only. A package consisted of six well labelled bottles each containing the number of tablets required in each of the six weeks of the intervention. Eligible patients were given a drug package consecutively working down the randomisation list. Clinicians and patients were blinded to the identity of the tablets. A randomisation code list was kept sealed and was released at the end of the study.
LABORATORY MEASUREMENTS AND FOLLOW UP ASSESSMENT

Pericardial fluid specimens $(5 \mathrm{ml})$ were immediately injected onto Lowenstein-Jensen slope and into double strength Kirchner medium, and transported to the National Tuberculosis Reference Laboratory in Bulawayo, for smear, culture, and identification of isolates. Pericardial fluid smears were stained for acid-alcohol fast bacilli using Ziehl-Neelsen stain. The CD4+ lymphocyte count was determined at recruitment by immunostaining of whole blood smears with a mouse anti-CD4 monoclonal antibody (Dako, Glostrup, Denmark). ${ }^{23}$ Visits were scheduled weekly for the first eight weeks, two monthly up to six months, then three monthly up to 18 months. Patients made additional visits whenever they felt unwell. At every visit patients were assessed clinically for features of ongoing tuberculosis, pericardial disease (effusion, tamponade, and constriction), side effects of medication (antituberculous drugs and prednisolone), sense of wellbeing, and functional capacity. Every two weeks during the first two months and subsequently at every visit laboratory tests, chest radiography, electrocardiography, and echocardiography were performed. Compliance was assessed by pill count at each visit during the period of drug treatment.

\section{ECHOCARDIOGRAPHIC EXAMINATION}

Two commercially available echocardiography machines (Phillips and Kretz) were used for echocardiographic examinations. JGH and IT with extensive experience of echocardiography in this setting performed all examinations. A standard protocol was used with examinations in the left parasternal long and short axes, apical two and four chamber and subcostal views. Additional views were dictated by the requirements of the individual case. Before the study the two cardiologists had joint sessions on 10 patients with large pericardial effusions and developed consensus on criteria for measurement of pericardial fluid size in the anterior, posterior, and subcostal views and the diagnosis of constrictive pericarditis.

\section{END POINTS}

The planned total observation period for each patient was 18 months from entry into the study, but patients continued to be seen until the censor date, 22 January 1997 . The primary end points were resolution of pericardial effusion and death. The secondary end points were resolution of pretreatment symptoms and signs, low voltage ECG, and corticosteroid related adverse effects. The diagnosis of constrictive pericarditis was made on the basis of a combination of clinical and echocardiographic features. ${ }^{24}$ We were interested in observing complications that could be attributed to the use of prednisolone in HIV infected individuals such as increased bacterial and viral infections, and the development of Kaposi's sarcoma. Low voltage on the ECG was defined as a QRS complex of $<6 \mathrm{~mm}$ in V5 or V6 and $<4 \mathrm{~mm}$ in the limb leads, a definition used in previous studies. ${ }^{18} 19$ 
STATISTICAL ANALYSIS

All analyses were performed on an intentionto-treat basis with two sided p values. Baseline characteristics were compared using Student's $t$ test and Kruskal-Wallis test for non-normally distributed continuous variables. The $\chi^{2}$ test with Yate's correction was used for categorical variables; where expected values were $<5$, the Fisher's exact test was used. The log rank statistic was used to compare the survival experience in the two treatment groups. Survival analysis was constructed using Kaplan-Meier plots. Values of $\mathrm{p}<0.05$ were regarded as significant. The statistical package STATA version 5 (Stata Corporation, USA) and SPSS-PC version 6.11 PROC MIXED were used for statistical analysis.

\section{Results}

All our patients were presumed to have contracted HIV infection through heterosexual contact. No patient admitted to homosexual or

Table 1 Baseline demographic and clinical characteristics

\begin{tabular}{|c|c|c|}
\hline & Prednisolone $(n=29)$ & Placebo $(n=29)$ \\
\hline Mean (range) age (years) & $33(19-53)$ & $29(21-41)$ \\
\hline $\operatorname{Sex}(M / F)$ & $22 / 7$ & $18 / 11$ \\
\hline \multicolumn{3}{|l|}{ Duration of illness (weeks) } \\
\hline Unknown & 1 & 1 \\
\hline$<2$ & 4 & 3 \\
\hline $2-8$ & 20 & 15 \\
\hline$>8$ & 4 & 10 \\
\hline \multicolumn{3}{|l|}{ Symptoms } \\
\hline Cough & 27 & 28 \\
\hline Sputum production & 22 & 22 \\
\hline Haemoptysis & 6 & 3 \\
\hline \multicolumn{3}{|l|}{ Dyspnoea } \\
\hline Nil & 3 & 5 \\
\hline On exertion & 16 & 18 \\
\hline At rest & 10 & 6 \\
\hline Chest pain & 26 & 23 \\
\hline \multicolumn{3}{|l|}{ Past medical history } \\
\hline Pneumonia & 2 & 2 \\
\hline \multicolumn{3}{|l|}{ Signs } \\
\hline Fever $\left(>37.7^{\circ} \mathrm{C}\right)$ & 16 & 18 \\
\hline \multicolumn{3}{|l|}{ Pulse (beats/min) } \\
\hline$\leqslant 100$ & 0 & 0 \\
\hline $101-120$ & 24 & 19 \\
\hline$>120$ & 5 & 10 \\
\hline \multicolumn{3}{|l|}{ Systolic blood pressure $(\mathrm{mm} \mathrm{Hg})$} \\
\hline$<100$ & 1 & 2 \\
\hline$\geqslant 100$ & 28 & 27 \\
\hline Pulsus paradoxus & 18 & 16 \\
\hline \multicolumn{3}{|l|}{ JVP $(\mathrm{cm})$} \\
\hline$\leqslant 5$ & 4 & 3 \\
\hline $6-10$ & 10 & 14 \\
\hline$>10$ & 12 & 8 \\
\hline \multicolumn{3}{|l|}{ Respiratory rate/min } \\
\hline Mean (range) & $29(18-46)$ & $30(18-44)$ \\
\hline \multicolumn{3}{|l|}{ Weight $(\mathrm{kg})$} \\
\hline Mean (range) & $57(42-75)$ & $54(35-67)$ \\
\hline \multicolumn{3}{|l|}{ Oedema } \\
\hline Nil/just detectable & 21 & 18 \\
\hline Affecting legs & 4 & 5 \\
\hline Affecting sacrum & 1 & 2 \\
\hline \multicolumn{3}{|l|}{ Ascites } \\
\hline $\mathrm{Nil} /$ just detectable & 26 & 22 \\
\hline Shifting dullness & 1 & 3 \\
\hline Tense abdomen & 0 & 0 \\
\hline \multicolumn{3}{|l|}{ Hepatomegaly $(\mathrm{cm})$} \\
\hline$\leqslant 4$ & 7 & 6 \\
\hline $5-8$ & 16 & 16 \\
\hline$>8$ & 4 & 3 \\
\hline \multicolumn{3}{|l|}{ Patients perception of wellbeing } \\
\hline Completely well & 0 & 0 \\
\hline Well but not perfect & 12 & 11 \\
\hline Unwell & 17 & 17 \\
\hline \multicolumn{3}{|l|}{ Level of physical activity } \\
\hline Unrestricted & 11 & 11 \\
\hline Out and about but restricted & 11 & 12 \\
\hline Restricted to home or hospital & 6 & 5 \\
\hline Bedridden & 1 & 1 \\
\hline
\end{tabular}

JVP, jugular venous pressure. bisexual activity or use of illicit intravenous drugs. None gave a history of transfusion of blood products in the past. There was no direct indication as to when each might have acquired HIV infection prior to the study.

\section{BASELINE DEMOGRAPHIC AND CLINICAL}

CHARACTERISTICS

Of the 58 patients entered into the study, 29 were randomised to prednisolone and 29 to placebo. There was no significant difference between the two treatment groups with regard to demographic and clinical variables (table 1). Generalised peripheral lymphadenopathy was noted in $81 \%$ of patients, but other HIV related features were infrequent and were comparable in the two groups.

\section{LABORATORY FEATURES}

Baseline haematologic, liver function tests, radiologic, electrocardiographic and echocardiographic findings were comparable between the treatment groups (table 2). Overall anaemia (haemoglobin $<12 \mathrm{~g} / \mathrm{dl}$ ) was found in $74 \%$ and hypoalbuminaemia $(<30 \mathrm{~g} / \mathrm{l})$ in $61 \%$ of patients; $54 \%$ of patients had CD $4+$ counts between 200 and 500 cells $/ \mu 1$.

CONFIRMATION OF TUBERCULOSIS DIAGNOSIS In total $22(38 \%)$ pericardial fluid specimens grew Mycobacterium tuberculosis on either Lowenstein-Jensen and/or double strength Kirchner media. Twelve cultures (41\%) in the prednisolone group and $10(35 \%)$ in the placebo group were positive for $M$ tuberculosis $\left(\chi^{2}=0.07, \mathrm{df}=1, \mathrm{p}=0.787\right)$.

REGRESSION OF PERICARDIAL EFFUSION: RADIOLOGICAL AND ECHOCARDIOGRAPHIC FINDINGS

Although prednisolone appeared to bring about a more rapid decrease in radiological cardiothoracic ratio and echocardiographic resolution of pericardial effusion (fig 1), these were not significant (figs 2 and 3 ).

MORTALITY

Kaplan-Meier plots of survival in prednisolone and placebo treated patients over 18 months of follow up are shown in fig 4. Three deaths occurred within one week of introduction of antituberculous treatment (one in the prednisolone and two in the placebo group). In the first six months of treatment nine deaths occurred among the 58 patients-one in the prednisolone group and eight in the placebo group. At the end of the study five deaths were recorded in the prednisolone group and 10 in the placebo group; the difference was significant $\left(\log \operatorname{rank} \chi^{2}=8.17 \mathrm{p}=0.004\right)$. Of the nine deaths which occurred in the six months of antituberculous treatment, three were caused by disseminated tuberculosis, five were caused by a combination of disseminated tuberculosis and ongoing active pericarditis, and one was caused by disseminated tuberculosis, active pericarditis, and possibly pulmonary Kaposi's sarcoma. None of these nine deaths were caused by constrictive pericarditis. Deaths after the six months of treatment were 
Table 2 Baseline laboratory findings

\begin{tabular}{|c|c|c|c|c|}
\hline & \multicolumn{2}{|c|}{ Prednisolone $(n=29)$} & \multicolumn{2}{|c|}{ Placebo $(n=29)$} \\
\hline Haemoglobin $(<12 \mathrm{~g} / \mathrm{dl})$ & \multicolumn{2}{|l|}{20} & \multicolumn{2}{|l|}{19} \\
\hline Total white cell count $(<4.0$ cell $/ \mu \mathrm{l})$ & \multicolumn{2}{|l|}{6} & \multicolumn{2}{|l|}{1} \\
\hline Neutrophil $(<1.8$ cell $/ \mu \mathrm{l})$ & \multicolumn{2}{|l|}{3} & \multicolumn{2}{|l|}{1} \\
\hline Lymphocyte $(<1.0$ cell $/ \mu \mathrm{l})$ & \multicolumn{2}{|l|}{1} & \multicolumn{2}{|l|}{4} \\
\hline Platelet count $(<100 \mathrm{cell} / \mu \mathrm{l})$ & \multicolumn{2}{|l|}{2} & \multicolumn{2}{|l|}{1} \\
\hline Median (interquartile range) CD $4+$ count $^{\star}$ & \multirow{2}{*}{\multicolumn{2}{|c|}{3}} & 254 & $(132-352)$ \\
\hline$<200$ cells $/ \mu 1$ & & & \multicolumn{2}{|c|}{5} \\
\hline $200-500 \mathrm{cells} / \mu \mathrm{l}$ & \multicolumn{2}{|l|}{10} & \multicolumn{2}{|l|}{5} \\
\hline$>500$ cells $/ \mu \mathrm{l}$ & \multicolumn{2}{|l|}{2} & \multicolumn{2}{|l|}{3} \\
\hline \multicolumn{5}{|c|}{ Median (interquartile range) values of liver function tests } \\
\hline Bilirubin & 11 & $(10-180)$ & 11 & $(10-27)$ \\
\hline Aspartate transaminase & 35 & $(5-520)$ & 32 & $(6-127)$ \\
\hline Alkaline phosphatase & 178 & $(145-361)$ & 237 & $(100-610)$ \\
\hline Albumin & 16 & & 12 & \\
\hline \multicolumn{5}{|l|}{ Cardiothoracic ratio (chest $x$ ray) $\dagger$} \\
\hline$<55 \%$ & \multicolumn{2}{|l|}{0} & \multicolumn{2}{|l|}{0} \\
\hline $55-75 \%$ & \multicolumn{2}{|l|}{9} & \multicolumn{2}{|l|}{6} \\
\hline$>75 \%$ & \multicolumn{2}{|l|}{5} & \multicolumn{2}{|l|}{8} \\
\hline ECG $\ddagger$ (low voltage) & \multicolumn{2}{|l|}{4} & \multicolumn{2}{|l|}{5} \\
\hline \multicolumn{5}{|c|}{ Mean (SD) pericardial effusion size on echocardiography $(\mathrm{cm})$} \\
\hline Anterior & \multicolumn{2}{|c|}{$2.5(2.1)$} & \multicolumn{2}{|c|}{$2.2(1.3)$} \\
\hline Posterior & \multicolumn{2}{|c|}{$2.6(1.0)$} & \multicolumn{2}{|c|}{$2.8(1.3)$} \\
\hline Subcostal & \multicolumn{2}{|c|}{$2.7(1.0)$} & \multicolumn{2}{|c|}{$2.7(1.0)$} \\
\hline
\end{tabular}

${ }^{\star} \mathrm{CD} 4$ cell counts were available on admission for 15 prednisolone and 13 placebo treated patients †Chest radiographs were available on admission in 14 prednisolone and 14 placebo treated patients.

$\ddagger$ ECGs were available on admission in 18 prednislone and 16 placebo treated patients.

caused by various HIV related conditions: HIV wasting disease (three patients), pneumonia (two patients), and meningitis (one patient).

MORBIDITY

Improvement in physical activity $(\mathrm{p}=0.02)$ and resolution of raised jugular venous pressure $(p=0.017)$, hepatomegaly $(p=0.007)$ and ascites $(\mathrm{p}=0.015)$ were faster in prednisolone treated patients compared with those given placebo. No significant difference was observed in the rate of resolution or in
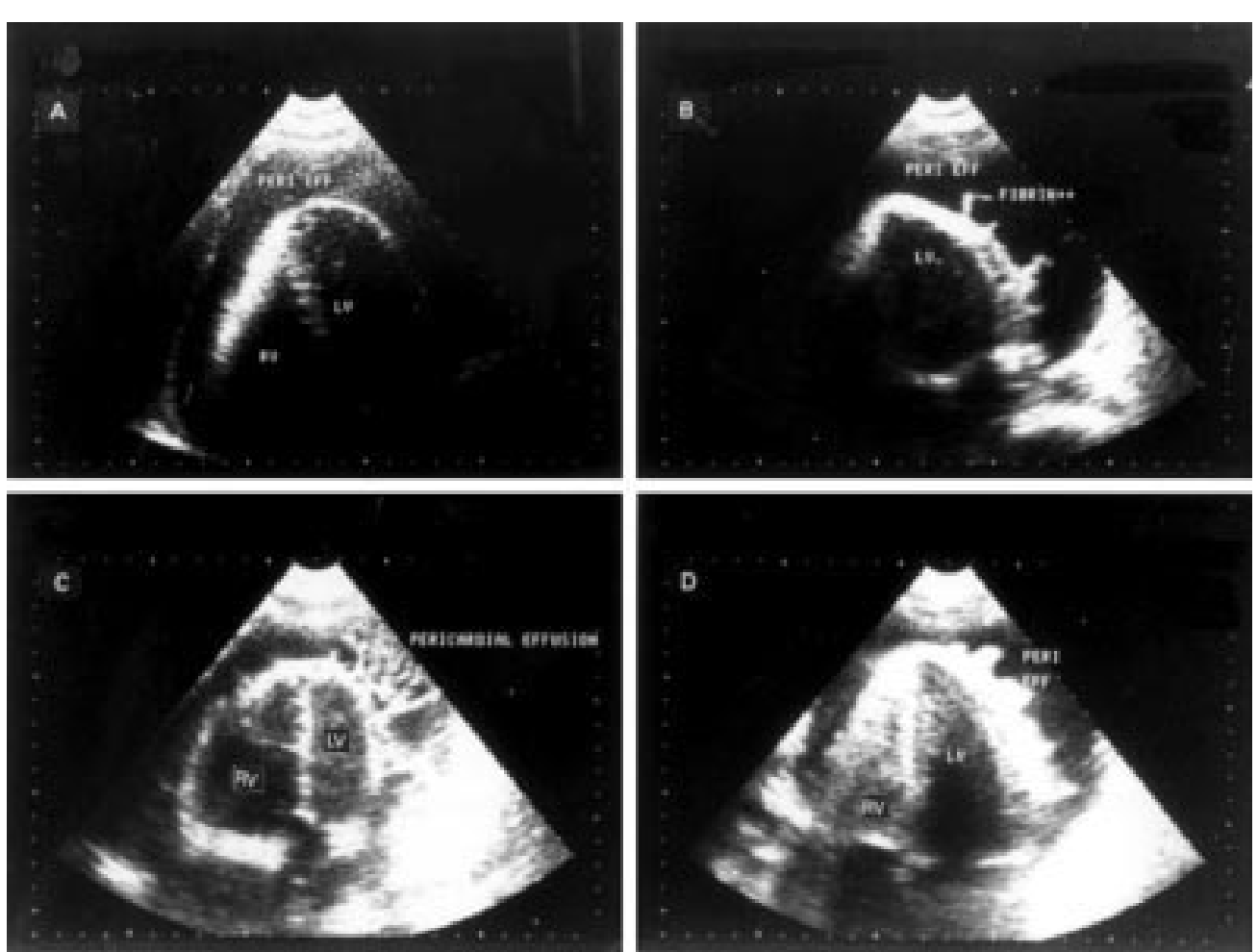

Figure 1 Echocardiographic apical views showing various appearances of tuberculous pericardial effusion in four study patients. (A) Effusion appears as a homogenous moderately echo dense collection. (B) Echo lucent fluid with fimbria-like fibrinous strands. (C) Fibrinous strands organised as clumps of meshwork within a mildly echo dense effusion. (D) A layer of shaggy fibrin arranged uniformly around the heart with no evidence of constriction. Peri eff, pericardial effusion; LV, left ventricle; $R V$, right ventricle.
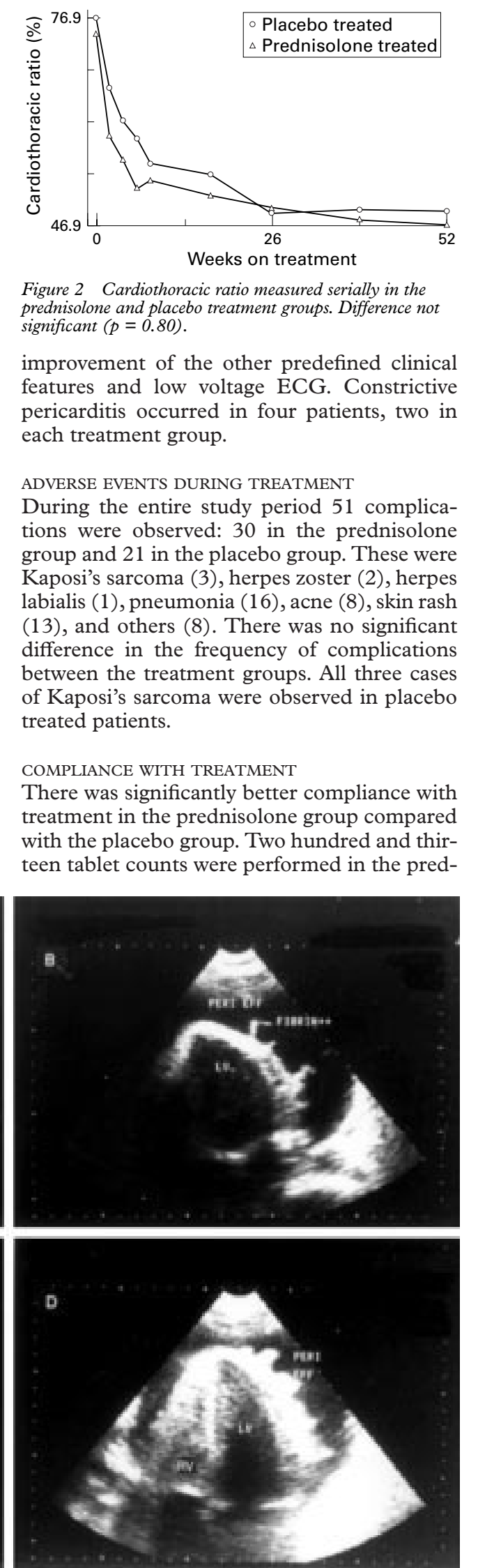

Figure 2 Cardiothoracic ratio measured serially in the prednisolone and placebo treatment groups. Difference not significant $(p=0.80)$.

improvement of the other predefined clinical features and low voltage ECG. Constrictive pericarditis occurred in four patients, two in each treatment group.

ADVERSE EVENTS DURING TREATMENT

During the entire study period 51 complications were observed: 30 in the prednisolone group and 21 in the placebo group. These were Kaposi's sarcoma (3), herpes zoster (2), herpes labialis (1), pneumonia (16), acne (8), skin rash (13), and others (8). There was no significant difference in the frequency of complications between the treatment groups. All three cases of Kaposi's sarcoma were observed in placebo treated patients.

COMPLIANCE WITH TREATMENT

There was significantly better compliance with treatment in the prednisolone group compared with the placebo group. Two hundred and thirteen tablet counts were performed in the pred- 

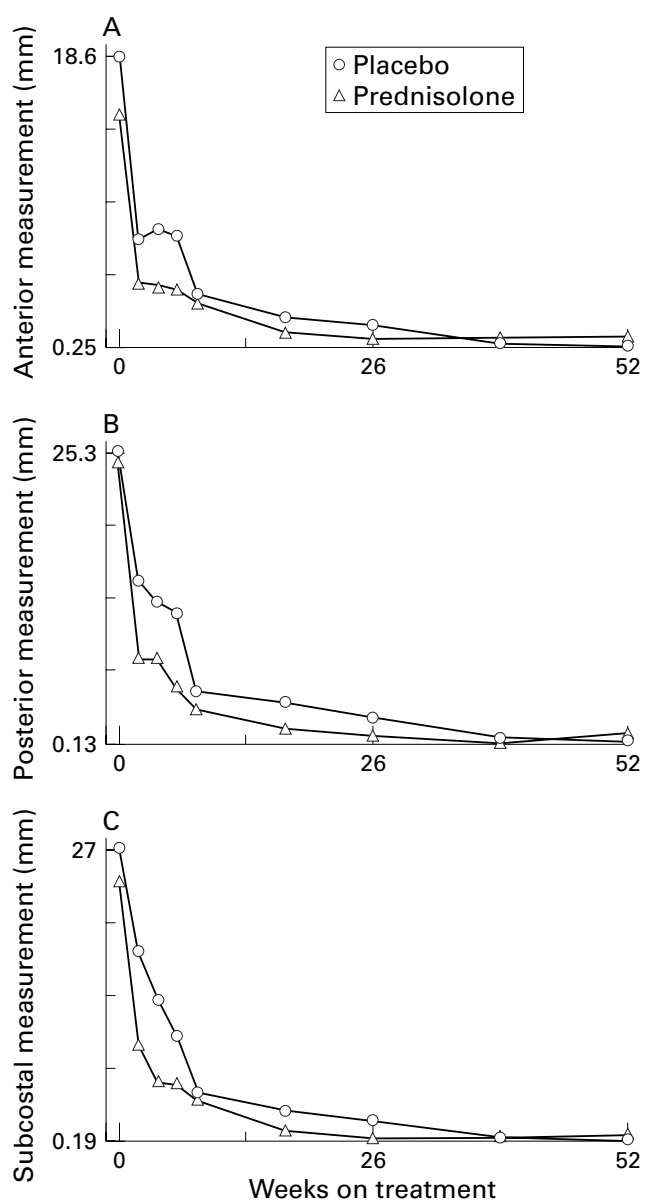

Figure 3 Pericardial fluid regression serial echocardiographic measurements of fluid in the $(A)$ anterior, $(B)$ posterior, and (C) subcostal views. Differences not significant: anterior $p=0.19$; posterior $p=0.80$; subcostal $p=0.39$

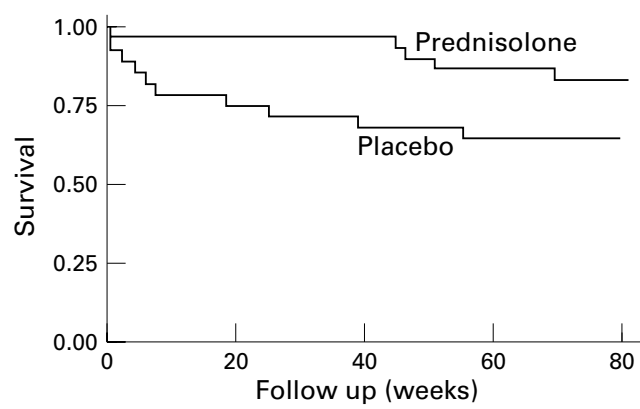

Figure 4 Kaplan-Meier plots of survival in prednisolone and placebo treated patients over 18 months of follow up. Significant difference in mortality, $\log$ rank $\chi^{2}=8.17$, $d f=1, p=0.004$.

nisolone group with $169(79.3 \%)$ counts showing that $>90 \%$ of tablets had been consumed. In the placebo group 182 counts were performed with $119(65.4 \%)$ counts showing that $>90 \%$ tablets were consumed $\left(\chi^{2}=9.73, \mathrm{df}=2, \mathrm{p}=0.008\right)$. However, there was no association between compliance and mortality during the six months of antituberculous treatment $(\mathrm{p}=0.104)$.

\section{Discussion}

TUBERCULOUS PERICARDITIS

There has been a rapid rise in the incidence of tuberculosis, with a disproportionate increase in extrapulmonary tuberculosis in sub-Saharan Africa, as a result of the HIV epidemic. ${ }^{25}$ In 1987 extrapulmonary tuberculosis accounted for $15.2 \%$ of tuberculosis cases in Harare city, but a decade later this figure was $23.5 \%$. $^{26}$

CORTICOSTEROIDS IN TUBERCULOSIS

The use of corticosteroids in conjunction with antituberculous drugs has been shown to be of benefit in HIV seronegative individuals with tuberculous pericarditis, meningitis, and pleural disease. ${ }^{27}$ Earlier uncontrolled studies suggested improved outcome in tuberculous pericarditis with their use, ${ }^{15}$ but it was only in the 1980s that randomised controlled studies have shown benefit, ${ }^{18}{ }^{19}$ though this has been disputed in a systematic review. ${ }^{20}$ In these studies adjunctive corticosteroid treatment reduced mortality and had favourable clinical effects. ${ }^{18}{ }^{19}$ However, these studies were carried out on HIV seronegative patients, and such benefit should not be extrapolated uncritically to an HIV population. The challenge to the conclusions that prednisolone had salutary effects in the treatment of tuberculous pericarditis ${ }^{20}$ the lack of randomised controlled studies in HIV seropositive individuals, and the suggestion of potentially serious side effects of the use of prednisolone in HIV seropositive patients offered a strong ethical justification for carrying out a placebo controlled trial.

We have shown that high dose prednisolone in addition to antituberculous drugs resulted in reduced mortality and quicker improvement of clinical features, but did not influence the resolution of pericardial effusion. Unlike in Strang and colleague's studies, ${ }^{18} 19$ there were no favourable effects of prednisolone on fever, pulse rate, and sense of wellbeing. However, our subjects were treated largely as outpatients, thus precluding day to day assessment of these features. Compliance was better in the prednisolone arm, probably a reflection of an improved sense of wellbeing in these patients. The findings in this study relate to effusive disease, and so additional studies would be needed to determine the effect of steroids in HIV seropositive individuals with effusiveconstrictive and actively constrictive tuberculous pericarditis.

CORTICOSTEROIDS IN HIV RELATED CONDITIONS Corticosteroids are of benefit in several HIV related conditions, including immune thrombocytopenia ${ }^{28}$ and lymphoid interstitial pneumonitis, ${ }^{29}$ and as adjunctive treatment in Pneumocystis carinii pneumonia. ${ }^{30}{ }^{31}$ It has also been postulated that steroid treatment may benefit HIV infection by reducing a putative autoimmune component to CD4 depletion. ${ }^{32}$ However, there are potentially harmful side effects that may occur from their use in HIV infected individuals. In particular, there is the problem of added corticosteroid related immunosuppression which may lead to a higher incidence of bacterial infections, herpes simplex and herpes zoster reactivation, and potential development of Kaposi's sarcoma. ${ }^{12}{ }^{13} 33$ In a non-randomised study of tuberculosis in HIV seropositive patients, Elliott and colleagues 
reported that $6 / 47(13 \%)$ patients on prednisolone compared with $2 / 118$ (2\%) nonprednisolone treated patients developed herpes zoster in a two year follow up. ${ }^{12}$ In the same study three patients who received prednisolone developed Kaposi's sarcoma compared to none who did not. There are, however, other reports of Kaposi's sarcoma actually resolving with steroid treatment. ${ }^{34}$ In our study Kaposi's sarcoma occurred only in patients who were not on steroids. The assessment of the putative complications of corticosteroid use in HIV seropositive patients will require careful observation of a larger number of patients. Nonetheless, in this study the therapeutic benefits of corticosteroids outweigh their adverse effects.

MORBIDITY AND MORTALITY

Tuberculous pericarditis is a serious condition with a high incidence of constrictive pericarditis and a high mortality rate. Constrictive pericarditis has been described in $11 \%$ of patients with effusive tuberculous pericarditis occurring within two years of diagnosis. ${ }^{18}$ In our series constriction was infrequent and developed in equal numbers of prednisolone and placebo treated patients. Constriction was observed early during the course of treatment, being seen within eight weeks of the start of treatment. It is possible that the rate of constriction is reduced by HIV infection. In general HIV infected individuals in our setting die early, leaving little chance for constriction to develop. High mortality rates of up to $40 \%$ have been quoted in tuberculous pericarditis patients even in an HIV seronegative population. ${ }^{35}$ Mortality from tuberculous pericarditis in HIV infected patients is high because of the occurrence of other HIV related diseases and the increased likelihood of disseminated tuberculosis. ${ }^{6}$

\section{CONCLUSION}

We conclude that HIV seropositive patients with effusive tuberculous pericarditis show a lower mortality rate (both at completion of antituberculous treatment (six months) and at the end of follow up) and a quicker rate of clinical improvement when adjunctive prednisolone is administered in the first six weeks of standard antituberculous treatment. We therefore recommend that in the absence of any specific contraindications, HIV seropositive individuals with effusive tuberculous pericarditis should receive adjunctive prednisolone.

We are indebted to CAPS(Pvt) Ltd for providing prednisolone and placebo tablets for the study and for financial support. The ing. We would also like to thank the following for various contriMrs P contributions: Dr T Doherty (study planning), Mrs P Manjoro (patient recruitment and follow up), Ms O Lowe (processing of tuberculosis specimens), Dr P Fitzgerald (statistical analysis), Professor PS Douglas (proofreading), and Professor RF Heller (proofreading).

1 Fitzgerald JM, Grzybowski S, Allen EA. The impact of human immunodeficiency virus infection on tuberculosis human immunodeficiency virus infectio

2 De Cock KM, Soro B, Coulibaly IM, et al. Tuberculosis and HIV infection in sub-Saharan Africa [review]. $7 A M A$ 1992;268:1581-7.

3 Narain JP, Raviglione M, Kochi A. HIV-associated tuberculosis in developing countries: epidemiology and strategies for prevention. Tubercle Lung Dis 1992;73:311-21.
4 Harries AD. Tuberculosis and human immunodeficiency virus infection in developing countries. Lancet 1990;335: virus in

5 Cegielski JP, Ramaiya K, Lallinger GJ, et al. Pericardial disease and human immunodeficiency virus in Dar es Salaam, Tanzania. Lancet 1990;335:209-12.

6 Pozniak AL, Weinberg J, Mahari M, et al. Tuberculous pericardial effusion associated with HIV infection: a sign of disseminated disease. Tubercle Lung Dis 1994;75:297-300.

7 Maher D, Harries AD. Tuberculous pericardial effusion: a prospective clinical study in a low-resource settingBlantyre, Malawi. Int $\mathcal{F}$ Tuberc Lung Dis 1997;1:358-64.

8 Elliott AM, Halwiindi B, Hayes RJ, et al. The impact of human immunodeficiency virus on mortality of patients treated for tuberculosis in a cohort study in Zambia. Trans R Soc Trop Med Hyg 1995;89:78-82.

9 Combs DL, O'Brien RJ, Geiter LJ. USPHS tuberculosis short-course chemotherapy trial 21: effectiveness, toxicity and acceptability. Ann Intern Med 1990;112:397-406.

10 Fowler NO. Tuberculous pericarditis. fAMA 1991;266:99103.

11 Allen MB, Cooke NJ. Corticosteroids and tuberculosis. BMF 1991;303:871-2

12 Elliott AM, Halwiindi B, Bagshawe A, et al. Use of prednisolone in the treatment of HIV positive tuberculosis patients. Q F Med 1992;85:855-60.

13 Gill PS, Loureiro C, Bernstein-Singer M, et al. Clinical effects of glucocorticoids on Kaposi's sarcoma related to the acquired immunodeficiency syndrome (AIDS). Ann Intern Med 1989;110:937-40.

14 Clifford CP, Davies GJ, Scott J, et al. Tuberculous pericarditis with rapid progression to constriction: prompt diagnosis and treatment are needed [clinical conference]. BMF 1993; 307:1052-4.

15 Rooney JJ, Crocco JA, Lyons HA. Tuberculous pericarditis. Ann Intern Med 1970;72:73-8.

16 Bhan GL. Tuberculous pericarditis. F Infect 1980;2:360-4.

17 Spodick DH. Tuberculous pericarditis [letter]. BMF 1994; 308:61.

18 Strang JIG, Gibson DG, Mitchison DA, et al. Controlled clinical trial of complete open surgical drainage and of prednisolone in treatment of tuberculous pericardial effusion in Transkei. Lancet 1988;ii:759-64.

19 Strang JIG, Gibson DG, Nunn AJ, et al. Controlled trial of prednisolone as adjuvant in treatment of tuberculous constrictive pericarditis in Transkei. Lancet 1987;ii:1418-22.

20 Mayosi BM, Volmink JA, Commerford PJ. Interventions for treating tuberculous pericarditis (Cochrane Review). In: The Cochrane Library 1999. Oxford: Update Software.

21 Chia BL, Choo M, Tan A, et al. Echocardiographic abnormalities in tuberculous pericardial effusion. Am Heart f 1984;107:1034-5.

22 Ministry of Health and Child Welfare. Essential drugs list for Zimbabwe. Harare: Ministry of Health and Child Welfare, 1994.

23 Manson DY. Immunocytochemical labelling of monoclonal antibodies by the APAAP immunoalkaline phosphate technique. In: Bullock GR, Pertusz P, ed. Techniques in immunocytochemistry. New York: Academic Press; 1988:25-42.

24 Feigenbaum H. Pericardial disease. In: Feigenbaum H, ed. Echocardiography, 4th ed. Philadelphia: Lea \& Febiger; 1986:548-78.

25 Elliott AM, Halwiindi B, Hayes RJ, et al. The impact of human immunodeficiency virus on presentation and diagnosis of tuberculosis in a cohort study in Zambia. 7 Trop Med Hyg 1993;96:1-11.

26 Anon. Situation of TB in Harare. In: City of Harare Health Report 1997. Harare: City of Harare, 1997.

27 Alzeer AH, Fitzgerald JM. Corticosteroids and tuberculosis: risks and use as adjuvant therapy. Tubercle Lung Dis 1993;74:6-11.

28 Ratner L. Human immunodeficiency virus-associated autoimmune thrombocytopenic purpura: a review. $f A M A$ 1989;86:194-8.

29 Rubeinstein A. Paediatric AIDS. Curr Probl Pediatr 1986;16: 361-409.

30 Gagnon S, Boota AM, Fischi MA, et al. Corticosteroids as adjunctive therapy for severe Pneumocystis carinii pneumonia in the acquired immunodeficiency syndrome: a doubleblind placebo-controlled trial. N Engl f Med 1990;323: 1444-50.

31 Montaner JSG, Lawson LM, Levitt N, et al. Corticosteroids prevent early deterioration in patients with moderately severe Pneumocystis carinii pneumonia and the acquired immunodeficiency syndrome (AIDS). Ann Intern Med 1990;113:14-20.

32 Saulsbury FT, Bringelsen KA, Normansell DE. Effects of prednisolone on human immunodeficiency virus infection. South Med F 1991;84:431-5.

33 Schulhafer EP, Grossman ME, Fagin G, et al. Steroidinduced Kaposi's sarcoma in a patient with pre-AIDS. Am 7 Med 1987;82:313-7.

34 Sangiorgi G, Orlandi A, De Nardo D, et al. Complete regression of iatrogenic Kaposi's sarcoma due to corticosteroid treatment in a patient with tubercular pericarditis: a case report. Ann Ital Med Int 1993;8:21-4.

35 Alvarez S, McCabe WR. Extrapulmonary tuberculosis revisited: a review of experience at Boston City and other hospitals. Medicine (Baltimore) 1984;63:25-55. 